Geopolítica(s) Revista de estudios sobre espacio y poder ISSN: 2172-3958

https://dx.doi.org/10.5209/geop.69300

\title{
El (im)posible retorno del Estado al primer plano ante una catástrofe global
}

Jaime Pastor $^{1}$

Recibido: 6 de mayo de 2020 / Aceptado: 10 de mayo de 2020

Resumen. La irrupción global de la pandemia ha provocado un encadenamiento de crisis en distintos ámbitos. El Estado parece haber recuperado una nueva centralidad para responder a los desafíos más inmediatos en el plano sanitario, securitario, económico y social en un contexto de crisis de la globalización neoliberal y de competencia geopolítica entre viejas y nuevas grandes potencias, pero también de agravación del cambio climático y de revalorización de lo público y lo común. Se abren distintos escenarios posibles para "el día después": el business as usual, el neosocialdemócrata y el que puede venir de los movimientos desde abajo que aspiran a otro mundo posible. Más allá de estas especulaciones, es la convivencia con la inseguridad ante el futuro la que será la normalidad en esta nueva era.

Palabras clave: pandemia de COVID-19; Estados; biopolítica; bienes públicos; comunes; proteccionismo; territorio.

\section{[en] The (Im)possible Return of the State to the Forefront in the Face of a Global Catastrophe}

\begin{abstract}
The global emergence of the pandemic has unleashed a series of crises in different areas. The state seems thus to have recovered a new centrality with responses to not only the most immediate challenges as pertains health, security, economic and social spheres within a context of crisis of neoliberal globalization and of geopolitical competition between old and new great powers; but also with responses to the worsening of climate change and the re-appreciation of the public and common domains. Different possible scenarios can appear "the day after": either business as usual or the neosocial-democratic recipe, or a bottom-up alternative that may arise from social movements aspiring to achieve another possible world. Beyond these speculations, in this new era the coexistence with future insecurities will be normal.
\end{abstract}

Keywords: COVID-19 pandemic; states; biopolitics; public goods; common domains; protectionism; territory.

1 Profesor de Ciencia Política, Departamento de Ciencia Política y de la Administración, Universidad Nacional de Educación a Distancia (UNED).

E-mail: jaime.pastor68@gmail.com 


\section{[pt] O (im)possível retorno do Estado ao primeiro plano diante de uma catástrofe global}

Resumo. O surgimento global da pandemia causou uma cadeia de crises em diferentes âmbitos. Os Estados parecem ter recuperado uma nova centralidade para responder aos desafios mais imediatos no plano da saúde, da segurança, da economia e do social em um contexto de crise da globalização neoliberal e de competição geopolítica entre grandes e velhas potências, mas também de agravamento das mudanças climáticas e de revalorização do público e do comum. Diferentes cenários possíveis são abertos para o "dia de amanhã": business as usual, o neosocialdemocrata e aquele que pode vir dos movimentos de baixo que aspiram a outro mundo possível. Para além dessas especulações, é a convivência com a incerteza diante do futuro a normalidade desta nova era.

Palavras-chave: pandemia da COVID-19; Estados; biopolítica; bens públicos; comuns; protecionismo; território.

Sumario. Introducción. 1. La nueva centralidad del Estado nacional protector. 2. Lo público y lo estatal. 3. ¿Qué escenarios? Referencias.

Cómo citar: Pastor, J. (2020). El (im)posible retorno del Estado al primer plano ante una catástrofe global. Geopolítica(s). Revista de estudios sobre espacio y poder, 11(Especial), 165-172.

\section{Introducción}

Ante la irrupción de la pandemia global, los análisis y reflexiones en torno a los factores que inciden en la sucesión de crisis que está generando a escala planetaria, así como las especulaciones y propuestas para "el día después" son ya innumerables y es difícil aportar algo nuevo ${ }^{2}$. Con todo, intentaré contribuir en estas notas a abordar algunos aspectos de esta crisis global, convertida ya en "un acelerador del tiempo histórico" (Baschet, 2020), un punto de inflexión que nos emplaza a afrontar las bifurcaciones que con mayor urgencia se plantean ahora al conjunto de la Humanidad en este siglo XXI.

Una crisis que es multidimensional y diferente de las vividas en el pasado y, sobre todo, de la más reciente de 2007-2008 por proceder de la expansión de un virus y no de la crisis del sistema financiero, y por haber obligado a la casi paralización de la economía productiva global. Diferente también porque introduce un factor de riesgo vital que hasta ahora se creía limitado a los países del Sur o del Este, pero que ahora ha venido para extenderse con toda su gravedad en el Oeste: el de la posible aparición de nuevas pandemias de manera cada vez más frecuente, al menos mientras sigamos en la era del Capitaloceno, ya que "el problema no son los virus: el problema es un sistema socio-económico expansivo (y hasta una dinámica civilizatoria" (Riechmann, 2020). Por eso, a partir de ahora hay que sumar este factor a los cuatro parámetros que superan el techo de sostenibilidad de la vida en el planeta, según un Informe de científicos publicado en 2015, y que afectan al clima, a la biodiversidad, al estado de los ciclos del nitrógeno y a los suelos (Tanuro, 2020).

2 Por mi parte, me remito al artículo "Covid-19, capitalismo y fin de la normalidad", Viento Sur, 27 de marzo de 2020. Recuperado de https://www.vientosur.info/spip.php?article15758 
En esta ocasión se ha manifestado primero mediante una crisis sanitaria, seguida por una crisis económica, cuyo alcance está todavía por ver pero que probablemente conduzca a una Gran Depresión, con sus consecuencias sociales cada vez más alarmantes. Con ellas se ha producido una agravación de las desigualdades sociales y de todo tipo que no hacen más que profundizar las fracturas ya existentes en nuestras sociedades y, muy especialmente, una segmentación mayor dentro de la clase trabajadora. Tendencias todas ellas que pueden erosionar más todavía las bases materiales necesarias para frenar el proceso de desdemocratización ya en marcha mucho antes de esta pandemia ${ }^{3}$.

La crisis sanitaria ha mostrado, hasta ahora al menos, su mayor gravedad en los países occidentales, la mayor parte de ellos afectados por las políticas neoliberales de recortes y privatizaciones y por su dependencia de un sistema industrial de aprovisionamiento deslocalizado para atender a situaciones de emergencia como la vivida ahora. A todo esto se ha unido el retraso en la respuesta ante esta pandemia, pese a los avisos que habían llegado desde distintos observatorios (Ramonet, 2020), confirmando el lastre del viejo supremacismo occidental que hacía pensar que nunca iban a llegar a estas tierras epidemias tan letales como las sufridas en otras regiones del mundo. Se ha llegado así a un colapso sanitario que ha tenido en personas mayores, pero también en un alto número de trabajadores de la sanidad y de los servicios sociales en general, los sectores más perjudicados por la falta de una política de prevención, capaz de poner los medios necesarios para asumir el desafío que suponía esta pandemia.

\section{La nueva centralidad del Estado nacional protector}

En medio de este contexto general, en el que ni la OMS ni otras instituciones y organizaciones internacionales han estado a la altura, estamos asistiendo a un mayor protagonismo de muchos Estados en la respuesta a la necesidad de garantizar la seguridad sanitaria, pero también la supervivencia de muchas empresas y la asistencia social, junto con las ONG y nuevas redes de apoyo mutuo, a los sectores sociales más afectados. En torno a esta cuestión se abre ahora una disputa por el sentido en el que deben orientarse los Estados en un contexto de crisis de la globalización neoliberal, refuerzo de tendencias nacional-proteccionistas e intensa competencia geoestratégica entre las grandes potencias, especialmente EE UU y China y sus alianzas respectivas en proceso de recomposición.

En efecto, la lucha contra la pandemia ha conducido a la mayoría de los gobiernos a proclamar el estado de alarma, acompañándolo de un discurso bélico que ha buscado cerrar filas en las poblaciones respectivas mediante la puesta en pie de planes de confinamiento, si bien con distintas variantes entre ellos, con el propósito común de "salvar vidas". Sin embargo, muy pronto hemos podido comprobar las tensiones entre ese objetivo y el de "salvar la economía" a medida que se ha prolongado esa situación de emergencia. Todo ello apoyado en una complicada regulación legal que ha permitido la limitación de determinadas libertades fundamenta-

Con mayor razón ahora porque, como constataba Adam Przeworski antes del estallido de la actual crisis: "While elites see democracy in institutional terms, several surveys indicate that mass publics often conceive of it in terms of "social and economic equality" (Przeworski, 2019, p.102). 
les, especialmente la libertad de movimiento, pero también de otras como la libertad de expresión y los derechos de reunión y manifestación, como ya hemos podido observar con ocasión de la celebración de la jornada del 1 de mayo en muchos países.

Una política de seguridad que, estimulada por las experiencias de China, pero también por las de países con regímenes demoliberales, como Corea del Sur, Taiwán o Singapur, está dando un salto adelante enorme en el uso de medios digitales, destinado a implantar un control del conjunto de la población que, justificado ahora por razones sanitarias, podría transformarse en normal "el día después". Se podría llegar por esta vía a imponer un control necrobiopolítico permanente de la población (Preciado, 2020), apoyado en una asociación cada vez más estrecha entre los Estados y los GAFAM (Google, Amazon, Facebook, Apple y Microsoft) del capitalismo digital. Una hipótesis nada despreciable porque, como se denuncia en el Manifiesto "La necesidad de luchar contra un mundo "virtual»", "un vistazo a la historia reciente de la tecnología muestra que los dispositivos liberticidas que se introducen en tiempos de crisis casi nunca desaparecen" "4 con la coartada en este caso de que, como ya he indicado antes, la amenaza de nuevas pandemias va a formar parte de nuestro futuro de inseguridad(es) permanente(s).

Es fácil comprobar, por tanto, el refuerzo del poder soberano de los Estados en el plano securitario, con las personas inmigrantes y demandantes de refugio como principales víctimas del cierre de fronteras, como ya ocurre desde hace tiempo en EE UU y en la UE, pero también dentro de las mismas, como estamos viendo también ahora en Grecia y en los países del Golfo. Un poder soberano que va a permitir su uso para el control de los espacios públicos virtuales y reales en los que se puedan expresar las distintas formas de protesta que no cuenten con el agrado de las autoridades afectadas; o, simplemente, para disuadir de la protesta, ya que como también se recuerda en el Manifiesto antes citado: "El hecho de saberse constantemente vigilado es fuente comprobada de conformismo y sumisión a la autoridad, incluso cuando no se vive en una dictadura".

Es también en el plano económico y social donde la recuperación de competencias por parte de muchos Estados es reclamada. Dada la magnitud de la catástrofe que se anuncia en cuanto al descenso del PIB, a la quiebra de un alto número de pequeñas y grandes empresas y, sobre todo, al aumento del paro, la precarización y el empobrecimiento de la mayoría de las poblaciones, la apelación al Estado como "salvador" es también recurrente. El debate está en qué escenario van a propiciar los Estados en un contexto en el que parece evidente la pérdida de credibilidad de algunas de las ideas-fuerza y de las políticas neoliberales en ámbitos como el de la sanidad y los servicios públicos en general. Empero, también lo es que, salvo que haya un cambio radical de la actual correlación de fuerzas social y política en algunos países clave del sistema-mundo, no parece probable a corto plazo que el sentido común neoliberal dominante hasta ahora vaya a verse sustituido por un buen sentido alternativo.

Lo anterior no supone olvidar que en el pasado el papel de los Estados ha sido también muy activo, sobre todo en su versión ordoliberal a través de su ensamblaje

4 Manifiesto "La necesidad de luchar contra un mundo «virtual»". CTXT: Contexto y Acción, 3 de mayo. Recuperado de https:/ctxt.es/es/20200501/Firmas/32143/riechmann-yayo-herrero-digitalizacion-coronavirusteletrabajo-brecha-digital-covid-trazado-contactos.htm 
creciente con el sistema financiero y a los mercados, ya desde la larga onda neoliberal iniciada a finales de los años 70 del pasado siglo y, tras el inicio de la Gran Recesión en 2007-2008, con mayor fuerza aplicando políticas de rescate a los bancos y medidas austeritarias contra las clases subalternas. Un proceso que en el ámbito de la Unión Europea y de la eurozona en particular condujo a la acentuación de las desigualdades entre el centro y las periferias del Sur y del Este, con Grecia como principal afectada, y que ahora probablemente se va a profundizar.

La novedad en el panorama con el que nos estamos encontrando ahora es que, en medio del agotamiento del ciclo de acumulación capitalista global y de nuevas tendencias proteccionistas en el plano comercial, los Estados van a tener que hacer compatibles, por un lado, un nuevo rescate al sistema económico y financiero y, por otro, la respuesta a una demanda creciente de lucha contra una catástrofe social muy superior a la iniciada en 2007-2008. Una vieja tensión entre la función de garantizar las condiciones de producción y reproducción capitalista y, a la vez, lograr un grado de legitimación suficiente entre las clases subalternas que no va a ser fácil de gestionar en esta coyuntura histórica. Máxime cuando deberían ser conciliadas con la urgente tarea de una necesaria transición energética y ecológica, cuyo retraso en abordar sigue contribuyendo a la aceleración del cambio climático.

Un conjunto de políticas estatales que exige un aumento extraordinario del gasto público para cubrirlas y que, de no ir apoyadas en una reforma fiscal radical, van a provocar un endeudamiento público y privado de magnitudes mayores que las conocidas hasta ahora. Una amenaza que puede verse atenuada si, como ya se reclama desde muchos países del Sur, se produce una cancelación de la deuda o, en el caso europeo, se llega a un acuerdo en torno a los fondos de solidaridad sin condiciones - lo cual exigirá el plácet nada fácil de la principal gran potencia, Alemania-, ya que, de no ser así, puede convertirse en una espada de Damocles para las futuras generaciones a escala global.

\section{Lo público y lo estatal}

Lo que sí va a ser difícil es que se repita el escenario de Business As Usual (BAU) que se aplicó en 2007-2008, aunque sin duda es lo que van a intentar las fracciones más transnacionalizadas de las clases dominantes. La revalorización de lo público y de las actividades esenciales, entre ellas todas las relacionadas con los cuidados, así como la necesaria respuesta a la catástrofe social que solo acaba de empezar son tan patentes que una salida similar a la anterior provocaría una creciente inestabilidad política y social de difícil gestión por parte de los gobiernos.

Con mayor razón cuando lo público no puede entenderse como un derecho del Estado sino como un deber, una obligación, ya que, como sostienen Pierre Dardot y Christian Laval (2020), "los servicios públicos no son los servicios del Estado en el sentido de que el Estado pueda disponer de ellos a su antojo, no son tampoco una proyección del Estado, son públicos en el sentido en que están 'al servicio del público". Lo mismo podríamos decir de cantidad de actividades que se han demostrado esenciales y que, por tanto, deberían escapar a la lógica del mercado interior y exterior (como es el caso de la industria farmacéutica), así como a las condiciones de sobreexplotación en las que se encuentran quienes trabajan en ellas. Una per- 
cepción que se está extendiendo al conjunto de bienes públicos y comunes dedicados a satisfacer las necesidades básicas de la población.

No cabe sorprenderse, por tanto, de que términos como nacionalizaciones o planificación económica y ecológica estén volviendo a la agenda política, incluso en boca de líderes políticos como el presidente francés Macron ${ }^{5}$. Habrá que ver si, como ocurrió con su antecesor Sarkozy en 2008, pronto esas palabras se olvidan para ser empleadas como un nuevo "socialismo para los ricos" o, por el contrario, se ponen al servicio de las mayorías sociales empobrecidas y bajo su control democrático.

En todo caso, la hipótesis de nuevas formas de capitalismo occidental en las que el Estado asuma un papel más activo y centralizado en la búsqueda de un modelo económico no tan dependiente del exterior, una política asistencial sustancialmente superior a la anterior a la crisis y, a su vez, un refuerzo del control social bajo formas más autoritarias, no parece descabellada. Sería un nuevo tipo de despotismo estatal (arropado por el saber experto sistémico) que aspiraría a una legitimación de ejercicio entre las poblaciones autóctonas, en nombre del miedo a la inseguridad permanente.

Con todo, esa tendencia podría ir acompañada de un reajuste parcial en el proceso de globalización vivido hasta ahora sin cuestionar, no obstante, la primacía del sistema financiero. Mientras tanto, la inestabilidad geopolítica seguirá su curso en un mundo en lucha por el control de los recursos y con nuevos alineamientos regionales, incluso dentro de una UE en "crisis existencial", como la definió uno de sus líderes políticos. Todo esto en medio de un proceso de cambio de relaciones de fuerzas entre las viejas y las nuevas grandes potencias, pero sin que "el repliegue internacional de un imperio [el estadounidense] que abandona su disfraz de auxiliador del mundo" (Katz, 2020) esté conduciendo a su crisis terminal (a semejanza de lo que significó la catástrofe nuclear de Chernóbil para la URSS o la crisis del Canal de Suez para Gran Bretaña) como hegemón. Su declive y repliegue etnonacionalista bajo Trump no le impide seguir contando, además de su poder militar, con los derechos de señoreaje sobre el dólar y ser sede madre principal de gran parte del capital transnacional que se ha extendido por el mundo, incluida China.

\section{3. ¿Qué escenarios?}

Especulando de nuevo sobre "el día después", tiene interés tomar en consideración tres escenarios de futuro posibles que propone Alain Bihr (2020): uno sería el del BAU, ya mencionado, otro el de una neosocialdemocracia adaptada a los nuevos tiempos del green-washing; y otro, en fin, el que podría abrir algunas brechas que permitieran ofrecer un horizonte alternativo distinto del actual modelo civilizatorio. Unos escenarios que pueden coincidir en lo fundamental con los que describía Luis González Reyes (2020) en otro artículo reciente, si bien poniendo más énfasis en la necesidad de responder a la crisis ecosocial global.

5 "Il nous faudra bâtir une stratégie où nous retrouvons le temps long, la possibilité de planifier, la sobrieté carbone, la prévention, la résilience qui seule peuvent permettre de faire face aux crises à venir", "Nous tiendrons". Le Monde, 13 de abril de 2020. 
En realidad, ya hemos visto un primer ensayo del primero en la tensión que se ha creado entre "salvar vidas" o "salvar la economía" a la hora de determinar cuáles eran los servicios esenciales a preservar en pleno confinamiento. Si Trump y Bolsonaro han sido los principales protagonistas en su defensa, no han faltado otros entre las derechas y los think tank de las grandes patronales de todos los países, empeñados incluso en establecer unos criterios monetarios del "valor de vida" (Husson, 2020), cuando no en un criterio de discriminación por edad para el tratamiento en los centros sanitarios.

Frente a ese proyecto, que podría convertirse en antesala de regímenes ecofascistas, otro escenario sería el que combinara, por un lado, un reforzamiento del sector público en la sanidad (health-washing) y servicios sociales en general más alguna forma de renta mínima para las capas más empobrecidas, y, por otro, un nuevo partenariado del Estado con las grandes empresas que asumiera algunos de los retos del Green New Deal compatibles con el fetichismo del crecimiento económico, como ya se propone desde distintos sectores políticos y sociales.

Finalmente, también se abre la posibilidad de una nueva ola de revueltas populares que tomen el relevo de las que estaban en marcha antes del estallido de esta crisis global y apunten hacia el tercer escenario. Movimientos como el feminista en Chile y otros países ya han sido motores de algunas de ellas, y el movimiento ecologista y las nuevas formas de sindicalismo social y barrial pueden llegar a serlo en otros, ocupando las plazas y las calles o/y bloqueando la economía y poniendo en el centro de la agenda política global propuestas como la socialización de los bienes públicos y comunes y el reparto de todos los trabajos; en resumen, apostando por un mundo justo, solidario y sostenible dentro de los límites biofísicos del planeta.

Se abre, en suma, una ventana de oportunidad para las peores distopías, pero también para reimaginar utopías creíbles y factibles, ya que, con palabras de Bruno Latour (2020): "En medio del dolor más extremo, estamos viendo que el orden mundial, que se nos decía que era imposible de cambiar, tiene una plasticidad asombrosa, y que, como colectivo, los seres humanos no están indefensos". Una plasticidad que se ha demostrado ya con la cantidad de dinero que de pronto se está dedicando por parte de los Bancos Centrales a "salvar a la economía" y que, como sugiere Baschet (2020), obliga a preguntarse por qué no se hace lo mismo para una transición ecosocial urgente capaz de frenar la verdadera catástrofe global que para la sostenibilidad de la vida en el planeta supone el cambio climático ya en marcha.

A las razones de las revueltas anteriores y a las derivadas de esta crisis global se suman ahora, además, las vividas durante el "Gran Confinamiento". Esta experiencia ha permitido innovar formas de protesta desde las redes sociales, pero ha dado un mayor valor a la necesidad del encuentro físico, a la interacción de los cuerpos y los afectos, a la discusión, a la deliberación y la acción colectiva anclada en el territorio, en el vecindario, en la fuerza de la gente. Sólo así se podrán recuperar las libertades y derechos políticos fundamentales ahora en cuarentena.

Pese a sus limitaciones, la escala local puede convertirse en un laboratorio a seguir de cerca para conocer la credibilidad y la viabilidad de los distintos escenarios posibles. En realidad, ya hemos visto prácticas prefigurativas de todos ellos en muchas ciudades, barrios y pueblos a lo largo de estos meses de confinamiento: el más autoritario y punitivista, el que propugna nuevos pactos de reconstrucción social y económica y el que, queriendo ir más allá, postula una nueva economía 
moral (revalorizando muchos trabajos invisibilizados y presionando por la reconversión de otros no esenciales, como el del automóvil), basada en una nueva relación entre lo urbano y lo rural, en la solidaridad y el apoyo mutuo.

Más allá de las especulaciones sobre los escenarios posibles, ya que habrá otros también en disputa, lo que sí es seguro es que entramos en una era en la que la incertidumbre ante el futuro frente a este encadenamiento de crisis será la normalidad en la que habrá que con-vivir y luchar.

\section{Referencias}

Baschet, J. (2020). Qu'est-ce qu'il nous arrive?. Lundimatin, 13 de abril. Recuperado de https://lundi.am/Qu-est-ce-qu-il-nous-arrive-par-Jerome-Baschet

Bihr, A. (2020). Tres escenarios para explorar el campo de lo posible. Viento Sur, 23 de abril. Recuperado de https://www.vientosur.info/spip.php?article15903

Dardot, P., y Laval, C. (2020). La dura prueba política de la pandemia. Infolibre, 30 de marzo. Recuperado de https://www.infolibre.es/noticias/lo_mejor_mediapart/2020/03/30/la_dura_prueba_polit ica_pandemia_105414_1044.html

González Reyes, $\bar{L}$. (2020). La época de los triajes. El Salto, 18 de abril. Recuperado de https://www.elsaltodiario.com/coronavirus/colapso-crisis-climatica-capitalismo-greennew-deal-decrecimiento-epoca-triajes

Husson, M. (2020). Sobre la vacuidad de la ciencia económica oficial: el arbitraje entre la actividad económica y los riesgos para la salud. Viento Sur, 29 de abril. Recuperado de https://www.vientosur.info/spip.php?article15929

Katz, C. (2020). La pandemia que estremece al capitalismo. I. Viento Sur, 21 de abril. Recuperado de https://www.vientosur.info/spip.php?article15892

Latour, B. (2020). La plasticidad en el orden mundial. El País, 3 de mayo. Recuperado de https://elpais.com/especiales/2020/coronavirus-covid-19/predicciones/la-plasticidaddel-orden-mundial/

Preciado, P. B. (2020). Aprendiendo del virus. El País, 28 de marzo. Recuperado de https://elpais.com/elpais/2020/03/27/opinion/1585316952_026489.html

Przeworski, A. (2019). Crises of democracy. Cambridge: Cambridge University Press.

Ramonet, I. (2020). La pandemia y el sistema-mundo. La jornada, 25 de abril. Recuperado de https://www.jornada.com.mx/ultimas/mundo/2020/04/25/ante-lo-desconocido-lapandemia-y-el-sistema-mundo-7878.html

Riechmann, J. (2020). La crisis del coronavirus desde el ecosocialismo gaiano. Viento Sur, (169), 11-18.

Tanuro, D. (2020). Pandemia, capitalismo y crisis climática. Viento Sur, 14 de abril. Recuperado de https://www.vientosur.info/spip.php?article15861 